\title{
Methodology for Design of an Intelligent Transport System (ITS) Architecture for Intermediate Colombian City
}

INGENIERIA TELEMÁTICA

\section{Metodología para el Diseño de una Arquitectura de un Sistema Inteligente de Transporte para una Ciudad Intermedia Colombiana}

\author{
Ricardo Salazar-Cabrera ${ }^{1}$, Álvaro Pachón ${ }^{2 \S}$ \\ ${ }^{1}$ Universidad del Cauca (Colombia), Department of Telematics. Popayan. Colombia \\ ${ }^{2}$ Universidad ICESI (Colombia) Department of ICT. Cali, Colombia \\ ricardosalazarc@unicauca.edu.co,§alvaro@icesi.edu.co
}

\section{Resumen}

Colombia presenta una de las más altas tasas de muertes por accidentes de tránsito comparada con el referente mundial. En particular, las ciudades intermedias del país superan la tasa nacional y la de las grandes ciudades. Las alcaldías y secretarías de movilidad han intentado solucionar este problema a través del desarrollo de servicios tecnológicos en el marco de los denominados Sistemas Inteligentes de Transporte (ITS). Sin embargo, en la mayoría de los casos, estos servicios no están basados en una arquitectura ITS adecuada, por lo cual, la interoperabilidad e integración de los servicios no resulta factible, genera altos costos y su implementación resulta compleja de llevar a cabo. El desarrollo de los servicios no utiliza una arquitectura ITS de referencia debido a que ésta no ha sido desarrollada. Aunque existen trabajos relacionados con metodologías de diseño de arquitecturas ITS regionales, no se cuenta con una metodología que considere diversas fuentes de referencia y el particular contexto de la ciudad. Para fomentar el desarrollo de servicios de movilidad, utilizando una arquitectura ITS adecuada, desarrollamos una metodología que permite su diseño en una ciudad intermedia de un país en desarrollo. Para formular la metodología, revisamos la documentación relacionada; identificamos las mejores prácticas; consideramos el alcance y contexto; y finalmente, definimos un proceso lógico que fuera sencillo de implementar. El presente artículo detalla la metodología de diseño que elaboramos y presenta los resultados obtenidos al aplicar la metodología en un caso en particular. La metodología obtenida permitió el diseño de una arquitectura ITS para la ciudad de Popayán, además consideramos que puede ser utilizada como herramienta para el desarrollo de arquitecturas ITS en contextos similares. La arquitectura ITS diseñada permite planear e implementar los servicios de movilidad de la ciudad de forma adecuada.

Palabras clave: Arquitectura, movilidad, sistemas Inteligentes de Transporte (SIT).

\begin{abstract}
Colombia has a high death rate due to traffic accidents, compared to the world reference. In particular, intermediate cities of the country have a very high death rate due to traffic accidents, much higher than the national rate and large cities rate. Municipalities and mobility secretariats have tried to solve these problems through the development of technological services, within the framework of the so-called Intelligent Transportation Systems (ITS). However, in most cases, these services are not based on an adequate ITS architecture, therefore, interoperability and integration of services is not feasible, generates high costs and its implementation is complex to carry out. The development of the services is not based on ITS architecture, due to the fact that this architecture has not been developed. Although there are works related to regional ITS architectural design methodologies, there is no methodology that considers diverse sources of reference and the particular context of the city. To encourage the development of mobility services, using an appropriate ITS architecture, we develop a methodology to design it in an intermediate city of a developing country. To formulate the methodology, we review the related documentation; we identify best practices; we consider the scope and context; and finally, we defined a logical process that was easy to implement. The present article details design methodology that we elaborate and presents the results obtained when applying the methodology in a particular case. Methodology obtained allowed the design of an ITS architecture for city of Popayán, in addition we consider that it serves as a tool for development of ITS architectures in similar contexts. ITS architecture designed will allow to plan and implement the mobility services of the city in an appropriate way.
\end{abstract}

Keyword: Architecture, Mobility, Intelligent transportation systems (ITS). 


\section{Introduction}

Traffic accidents were one of the most important causes of death worldwide in $2015^{(1)}$. However, number of deaths worldwide (for this cause) has stabilized since the year $(2013)^{(1)}$, which has not occurred particularly in countries such as Colombia, where death rate (per 100,000 inhabitants) has increased due to accidents transit, from 12,53 in 2010 to 14,28 in $2015^{(2)}$. According to statistical data by cities in Colombia ${ }^{(2-3)}$, although most large cities have death rates close to or below the national rate, intermediate cities significantly exceed national rate. City of Popayán (capital of the Department of Cauca, Colombian intermediate city of approximately 400,000 inhabitants) is no stranger to this situation, has one of the highest accident death rates in country, from 18,28 in 2011 to 21,26 in $2015^{(1)}$.

The main causes identified of these traffic accidents in Colombian cities are: disobedience to traffic regulations and speeding, which are directly related to traffic management ${ }^{(3)}$.

Some cities in the country (mainly large and intermediate cities) have developed technological services of urban mobility, with the objective of minimizing the occurrence of traffic accidents due to causes related to deficiencies in traffic management. These services have been developed within framework of the so-called Intelligent Transportation Systems (ITS).

ITS are an important option for sustainable mobility ${ }^{(4)}$. These systems increase transport efficiency, promote safety and improve mobility ${ }^{(5)}$. Conversely, traditional strategies to improve mobility are based on increasing the capacity of road infrastructure and number of vehicles, which are not sustainable from points of view: economic, spatial and environmental.

ITS services developed for the Colombian cities, in most cases, meet the requirements that were determined and contribute partially to solutions. However, each of services is developed independently, without taking into account whole panorama of mobility and related aspects of the city. So when trying to interoperate or integrate these services it is not easy to do it and sometimes there is no viability.

These negative aspects in the development of ITS services can be solved by designing and using ITS architectures for cities. ITS architectures provide a reference on what mobility services should be implemented, what priorities exist, and what processes and functionalities should be implemented.

Another important aspect related to ITS architecture for a Colombian city is the difference related to mobility between large and intermediate cities in the country. These differences include: number of inhabitants, area occupied by the city, movements of the population, economic activities, means of public transport, road infrastructure and transportation budget. Low annual budget in transport, limitations in road infrastructure, and characteristics of the means of public transport of intermediate cities do not allow a high investment in integral technological solutions to solve problems of road safety and traffic.

The intermediate cities implement specific solutions to the urgent identified problems, through suppliers that adjust to available budgets, which does not represent a real solution to problem. On the other hand, although large cities also have mobility problems, these cities have better budget conditions that allow them to implement policies and partial solutions in mobility. Therefore, Colombian intermediate cities in particular urgently need to develop an ITS architecture that adjusts to special conditions and limitations.

To facilitate the design of ITS architecture for intermediate cities, we initially developed a methodology that included judicious review of relevant ITS architectures, at international and national level, methodologies of design of regional ITS architectures, and the particular context of an intermediate city in a developing country. We compiled best practices and relevant aspects 
adaptable to context, of each of the mentioned sources, and we established a logical structure in stages that could be logically followed. Once methodology was developed, it was applied in design of ITS architecture of the city of Popayán.

The purpose of this paper is to present our methodology for design of ITS architecture for an intermediate city in a developing country, and also to present an example of application of this methodology in design of proposal for the ITS general architecture for city of Popayán.

The structure of following sections of article is as follows: section 2 presents related works; section 3 presents methods used for development; section 4 presents results obtained, mainly, with respect to ITS architecture formulated and a discussion about it; finally, section 5 presents conclusions and perspective.

\section{Related works}

Applications of Intelligent Transportation Systems use for transportation safety, efficiency and user services. The main applications in ITS are: Electronic Toll Collection (ETC), Highway Data Collection (HDC), Traffic Management Systems (TMS), Vehicle Data Collection (VDC), Transit Signal Priority (TSP), and Emergency Vehicle Preemption (EVP) ${ }^{(6)}$.

Yokota and Weilland formulated a proposal to implement ITS architecture in developing countries $^{(7)}$. The authors presented four criteria that they considered relevant in construction of architecture: affordability, regional compatibility and integration, geopolitics and technical aspects. This proposal was presented more than thirteen years ago and versions of evaluated architectures have been updated several times. In addition, a clear and detailed methodology for design of ITS architecture is not established, although criteria are mentioned and a basic process of four activities is proposed.

In 2006, United States Department of Transportation presented a proposal to "Develop, use and maintain a regional ITS architecture" (8). Authors established 6 steps to perform the development, use and maintenance activities of ITS architecture. This proposal ${ }^{(8)}$ was presented more than 11 years ago, although some aspects are still valid. Application of the proposal is limited exclusively to American architecture, excluding the possibility of incorporating other relevant aspects of other architectures.

FRAME architecture was proposed for development of a regional architecture ${ }^{(9)}$. Authors proposed to initiate meetings with stakeholders to obtain the "needs of the user". With these needs, and applying the framework, functional point of view is obtained, from which it is possible to derive its physical view.

Last two proposals presented ${ }^{(8-9)}$ coincide in several points, especially the one related to starting from a functional view of architecture to generate other points of view. However, application contexts are very different from what is proposed in this paper. Belinova et al. affirmed that there are two basic different approaches to ITS creation and implementation, represented by the FRAME Architecture, and the National ITS Architecture of the $\mathrm{USA}^{(10)}$. The principal differences lie in the manner and the flexibility of their use.

In Latin American countries such as Chile and Brazil important advances in ITS architectures were identified at the national level, mainly related to American architecture, but no progress was detected in ITS architectures at a regional level or in a particular city, nor on methodologies that allow the design of these regional ITS architectures.

With respect to national reality, mayors' offices and mobility secretariats of main cities of country (Bogotá ${ }^{(11)}$, Medellín $^{(12)}$, Cali and Bucaramanga) provides information of services provided, but they do not provide information on ITS architecture taken as reference.. This situation may indicate that, rulers of cities have not considered any ITS architecture, despite the fact that country has ITS initiative at a national level, 
called "National ITS architecture"(13). National architecture is an adaptation of the year 2010 of American architecture, which unfortunately no updates have been made since that date.

Also in the national environment, a proposal was presented for the development of ITS services for Colombian cities $^{(14)}$. Authors used the national ITS architecture of Colombia and resorted to methodological support described in American architecture, in order to formulate a model for the development of new services that allow the interoperability, compatibility and expansion of technologies and services in ITS architecture. Authors work was mainly focused on development of a service model, however, it did not present a design methodology for ITS architecture, as it is intended in our work.

Finally, also at a national level, a proposal for an architecture of a fundamental component in an ITS, an Advanced Public Transport Systems APTS, is presented, specifically for a region of the country ${ }^{(15)}$. The proposed architecture is based on the American ITS architecture and presents an important advance in the development of this type of architecture for a specific region, however it does not carry out the design applying a proposed methodology or one that is already implemented.

In the systematic review of literature, looking for documents generated at most 12 years ago, no works of ITS architecture designs were found for Colombian cities (or any other similar country) that used methodologies developed considering reference architectures and city context, as proposed in this paper.

\section{Methods}

The research scope is descriptive, at least in this first stage. It describes the methodology that we propose to carry out to design an ITS architecture for an intermediate city, additionally presents the application of this methodology in a specific city. To design ITS architecture for an intermediate city, we decided to review the following documentation: reference ITS architectures with worldwide application ${ }^{(16-18)}$, papers related to development of ITS architectures at a regional level and study of the particular conditions of an intermediate city.

The reference architectures and the methodologies of design of regional architectures are consulted online, because information by this means is permanently updated. We also obtained digital copies of ISO $14813^{(18)}$ through the educational institutions (universities) to which we are attached. Queries to the most used literature databases are made using the research resources provided likewise by the universities. Finally, consultations on ITS services to the mobility secretariats are carried out personally (Popayán and Medellín) and through electronic consultations (Bogotá, Cali and Bucaramanga).

After reviewing the aforementioned documentation, we determined to develop a methodology to achieve objective (architecture design), considering to obtain greater clarity, organization and ease of later use. Additionally, we took into account that a methodology could serve as a model to formulate ITS architectures of cities with such context in the country or countries similar to Colombia.

Subsequent to the development of methodology, we designed ITS architecture for an intermediate Colombian city in particular (Popayán) applying steps established in methodology. To graphically represent each of stages, we use a good practice used in description of project management methodologies of Project Management Institute. The 4 proposed stages for methodology are the following.

\subsection{Review of reference ITS architectures}

In Figure 1, the first stage of methodology that we propose are presented. At this stage, a revision of the next documents must be done: updated versions of representative architectures at international level, standards (proposal of ISO), national architecture, and regional (or city) architectures designed. 
Service areas, that each reference architectures considers, is one of the comparison factors in the review. Use of a matrix facilitates identification of services included for each architecture, the matrix would have as rows the service areas to be considered and as columns the ITS architectures. The selected service areas to be taken into account will be the sum of the ones that each architecture has, without repeating them. The number of ITS architectures in the matrix will depend on each case, although it is recommended to take into account at least the main international architectures, ISO standard and National architecture.

Objective of this stage of the methodology is to determine a reference ITS architecture by selecting some of the revised proposals, identifying (as a complement) relevant aspects of other reference architectures.

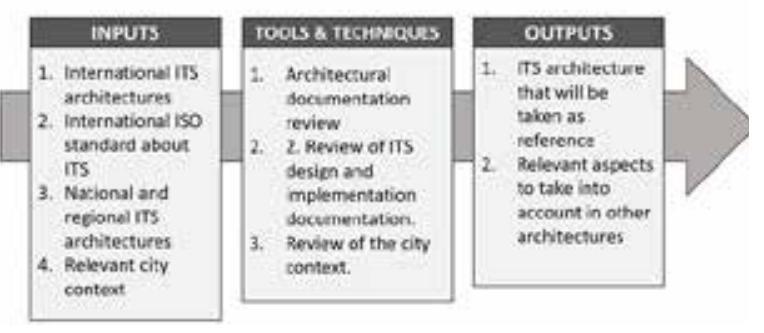

Figure 1. Proposed Design Methodology.

\subsection{Analysis of the city context}

In Figure 2, the context analysis stage is presented. Outputs from previous stage are used as inputs to this stage. Context of the city, other entry in this stage, should be analyzed in a broader sense.

In addition to the aforementioned review of services of the reference architecture, a context analysis tool should be used in this stage. Authors recommend PESTLE ${ }^{(19)}$. PESTLE allows evaluation of political, economic, social, technological, legal and environmental aspects of the city, related to mobility, transport infrastructure, means of transport used and related normative documents. As a result of stage, the special considerations of the city context must be obtained.

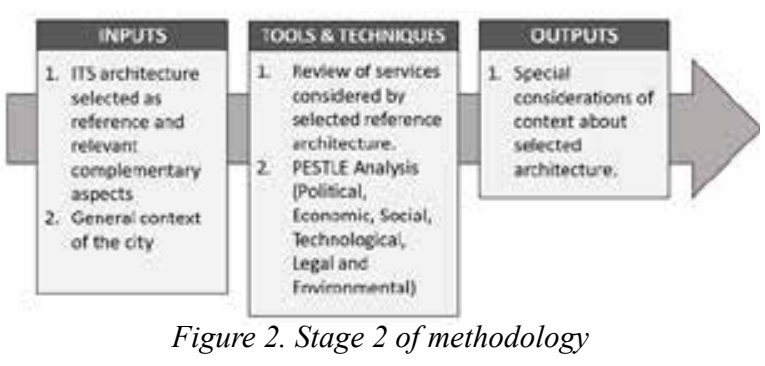

\subsection{Determination of architecture components}

In Figure 3, determination of architecture components stage is presented. Outputs obtained in stages 1 and 2 are used as inputs in this stage. Additionally, specific components that must be identified to present ITS architecture of the city, should be considered as input to this stage. Some components, which make up the views of ITS architecture of the city, vary depending on the architecture that was taken as a reference. Stakeholders, their needs and services provided are common components in revised reference architectures, while other elements are particularly used by one or another architecture.

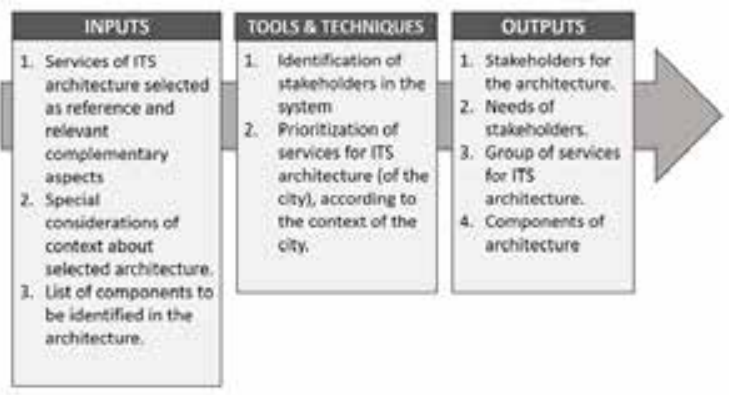

Figure 3. Stage 3 of methodology

For the identification of stakeholders, it is recommended to review documents such as: history of projects related to mobility and transport in the city, ITS architecture documents in other similar international cities and information provided by local government entities. Once the stakeholders have been identified, it is recommended to evaluate them by analyzing their level of influence and position on a possible ITS for the city, to determine whether or not it is taken into account for the needs analysis. 
When determining the stakeholders to consider for the ITS architecture, their needs are determined through interviews, surveys and the help of the previously mentioned documents. Then the needs with the largest number of involved stakeholders and high or medium level of influence will be considered.

With the determined needs, we proceed to identify the specific services (of the areas used in the matrix) that will be taken into account for ITS architecture. The selected services will be a subset of services that the reference architecture has, adding relevant services of other architectures. These selected services must meet the specific needs of the stakeholders. Finally, once the specific services to be provided in the ITS architecture have been determined, the components required in ITS architecture are identified. The specific components to be identified will depend on the ITS architecture selected as a reference.

\subsection{Design of the views of the ITS architecture}

In Figure 4, the final stage of methodology is presented. Outputs of stage 3 are presented in this stage as inputs. A design tool should be used to

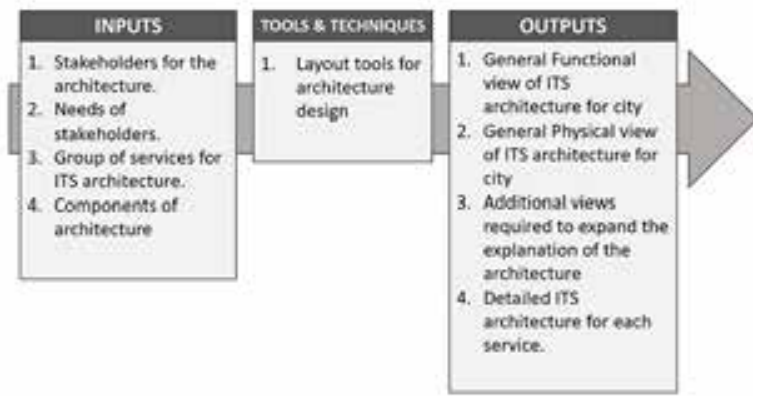

Figure 4. Stage 4 of methodology

present the views of ITS architecture. These views can use the type of diagram that uses reference ITS architecture or can use a standard language of systems description.

In addition to views of the general ITS architecture, ITS architectures detailed by each of services must be implemented. The detailed architecture of each services employs a subset of that components.

An integral flow chart of the methodology (with four stages, inputs, and outputs), is presented in Figure 5.

At the point of discussion of this document, it is specified the specific contribution of the work done with our proposed methodology and the application case.

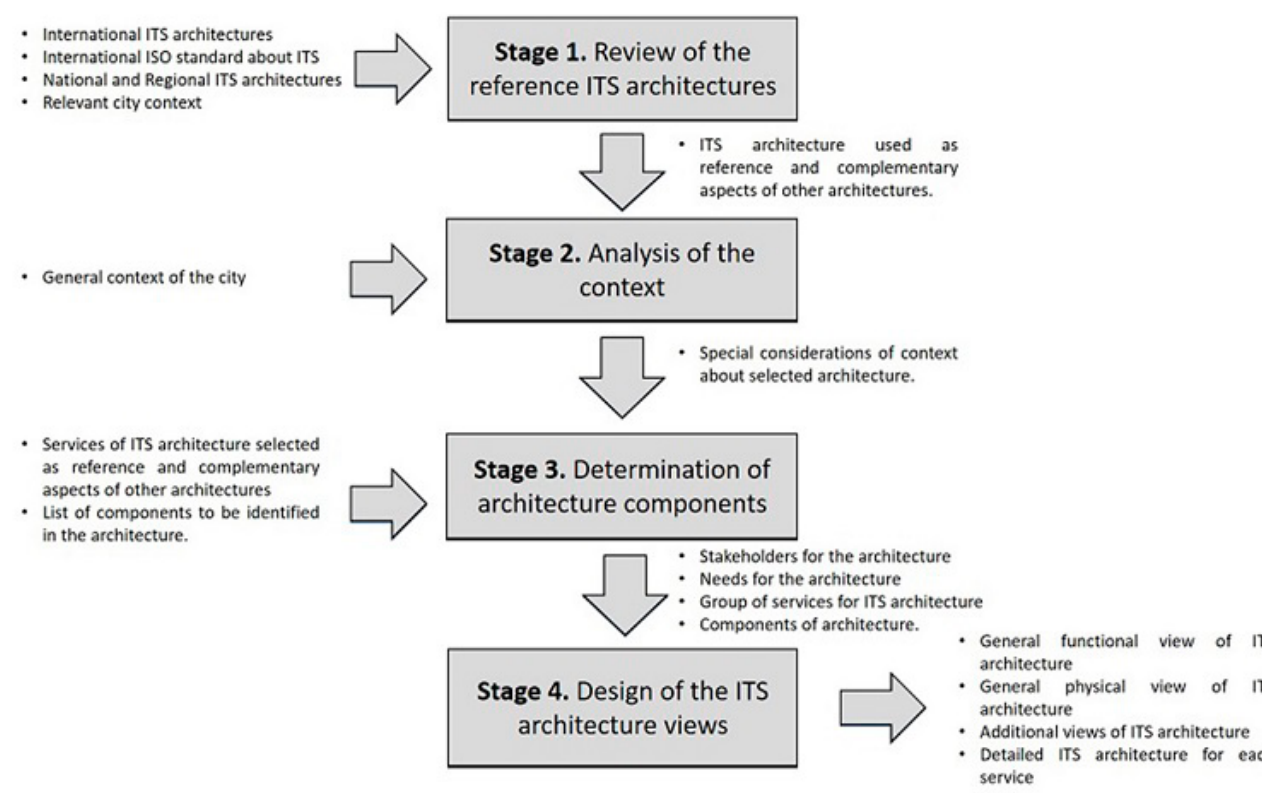

Figure 5. Integral flow chart of methodology 


\section{Results and discussion}

Main results of research developed are: methodology for design of ITS architecture and ITS architecture designed for the city of Popayán developed following one by one the stages described in methodology.

The methodology proposed by the authors has already been revised, so that the four important results by applying the methodology for the city of Popayán and a final discussion on it will be presented below.

\subsection{ITS architecture to be used as reference and complements of other architectures}

For the determination of appropriate reference ITS architecture for the city of Popayán, we compared the following ITS architectures: American ITS architecture (called ARC-IT) ${ }^{(16)}$, architecture of the European Union (called FRAME) ${ }^{(17)}$, architecture proposed by ISO in standard $14813^{(18)}$, and Colombian architecture ${ }^{(13)}$. We use the service areas in which all the revised architectures are focused, the vast majority are common service areas for all architectures, however, the exclusive service areas of some architectures were also taken into account. Comparison was made using a matrix (presented in Figure 6) that identified which is the architecture which covered most of the service areas.
To determine the adequate ITS reference architecture some relevant aspects of city context were considered too. Repeated disobedience of the traffic rules by pedestrians and drivers in the city and country in general, limited road infrastructure of the city (affected by maintenance works of public services), and high accident rates previously presented in this paper were considered in decision, selecting an ITS architecture that focuses on these aspects.. It was determined that most suitable ITS architecture for the city was ARC-IT. To this architecture was added service area of FRAME architecture called "Compliance with the law", considered relevant by the aforementioned on the disobedience of traffic regulations. Additionally, "Performance Management" services area proposed in the ISO architecture, also included as a complement, because it provides a tool for continuous improvement of designed ITS.

\subsection{Special considerations of the general context of the city of Popayán}

The context analysis called PESTLE ${ }^{(19)}$ was selected to identify and weight the particular political, economic, social, technological, legal and environmental conditions that are relevant in the design of the ITS architecture of the city. As a result of the application of this tool, the following information relevant to the context of the city was obtained:

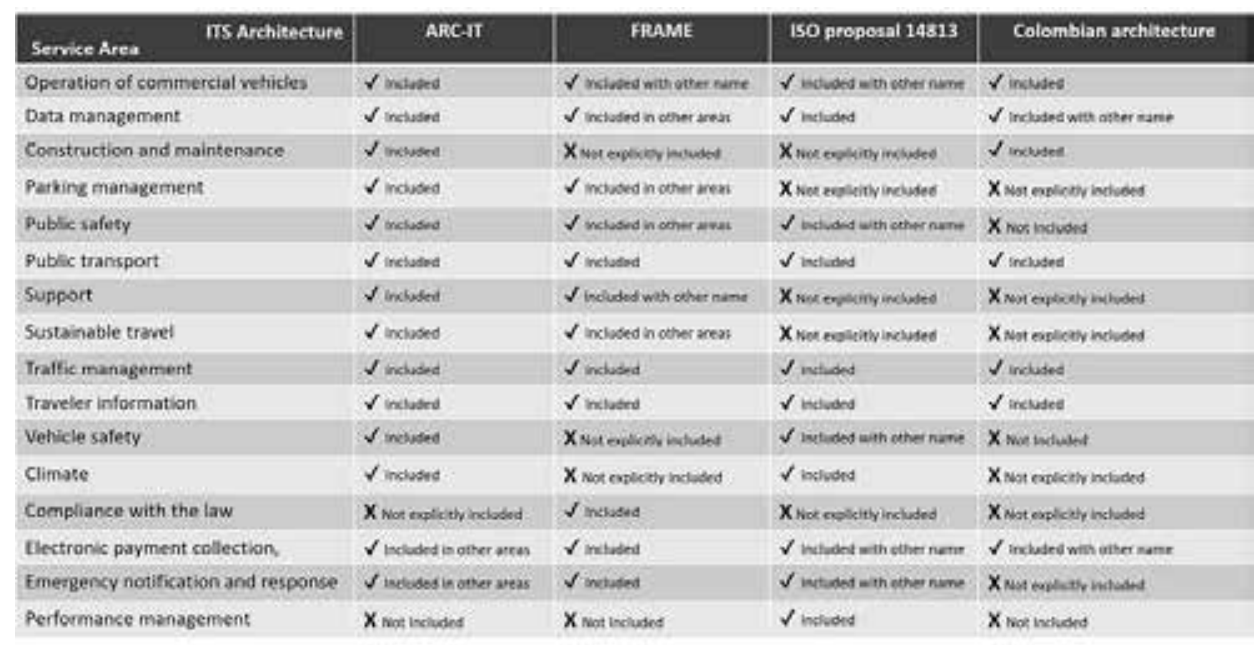

Figure 6. Comparison of ITS architectures by covered service areas to determine a reference 
The city of Popayán, intermediate Colombian city, located in the southwest of the country, is one of the oldest and best preserved cities of the American continent, which is reflected in its architecture and religious traditions. The city has an area of $512 \mathrm{~km}^{2}$ and 400,000 inhabitants (aprox). According to the socioeconomic studies (carried out by the Chamber of Commerce), the main economic activities of the city are commerce, accommodation and food services and manufacturing industry.

The city of Popayán and the majority of Colombian cities are highly influenced culturally, socially, economically and technologically by the American culture, rather than by the European culture. The current public transport system has major problems in efficiency, safety and reliability.

\subsection{Stakeholders, needs and group of services selected for ITS architecture of the city}

Using the aforementioned tools (presented in methodology), we identified the following stakeholders:

- Secretariat of Transit and Transportation of Popayán
- Secretariat of planning of the Popayán

- Ministry of Transport

- Public transport companies within the city.

- "Movilidad Futura" company (in charge of the Public Transport System to be implemented)

- Entities in charge of road emergencies (Fire Department, Metropolitan Police)

- Financial institutions

- Parking lots of the city

- System operator of the ITS

- System User (Traveler, Driver, Pedestrian)

After identifying the stakeholders, we evaluated their level of influence and positioning (presented in Figure 7) to determine which of the stakeholders would take their needs into account.

We identified the needs of the selected stakeholders, through the tools mentioned in the methodology. Once identified, we evaluate them (using information presented in Figure 8) to determine what need was required by certain stakeholders y what needs would be taken into account in the ITS architecture.

Prioritized needs of stakeholders, special considerations identified in the context of the city, service packages described in the reference architecture, were taken into account for determination of the services.

\begin{tabular}{|c|c|c|c|c|}
\hline Identifier & Stakeholder & $\begin{array}{l}\text { Level of } \\
\text { influence }\end{array}$ & Positioning & $\begin{array}{l}\text { Take into account } \\
\text { the architecture }\end{array}$ \\
\hline 1 & $\begin{array}{l}\text { Secretariat of Transit and Transportation of } \\
\text { Popoyán }\end{array}$ & HIGH & Positive & YES \\
\hline 2 & Secretariat of planning of the Popoyán & HIGH & Positive & YES \\
\hline 3 & Ministry of Transport & Low & Positive & NO \\
\hline 4 & Public transport companies within the city & MEDIUM & Undetermined & YES \\
\hline 5 & $\begin{array}{l}\text { "Movilidod Futurd" company (in charge of the } \\
\text { Public Transport System to be implemented) }\end{array}$ & MEDIUM & Undetermined & YES \\
\hline 6 & $\begin{array}{l}\text { Entities in charge of road emergencies (fire } \\
\text { Department, Metropolitan Police) }\end{array}$ & MEOIUM & Positive & YES \\
\hline 7 & Financial institutions & Low & Neutral & No \\
\hline 8 & Parking lots of the city & MEDIUM & Undetermined & YES \\
\hline 9 & System operator of the IIS & HIGH & Positive & YES \\
\hline 10 & System User (Traveler, Driver, Pedestrian) & MEDIUM & Positive & YES \\
\hline
\end{tabular}

Figure 7. Evaluation of Stakeholders identified 


\begin{tabular}{|c|c|c|c|c|}
\hline $\begin{array}{l}\text { Id of } \\
\text { need }\end{array}$ & Need & $\begin{array}{l}\text { Selected Stakeholders } \\
\text { involved Ids }\end{array}$ & Priority & $\begin{array}{l}\text { Take into account } \\
\text { in the architecture }\end{array}$ \\
\hline 1 & Reduction of the accident rate in mobility. & $1,2,4,5,6,10$ & High & YES \\
\hline 2 & Compliance with traffic regulations by drivers and pedestrians & $1,2,4,5,6,10$ & High & YES \\
\hline 3 & Historical information on transfers made by travelers & $1,2,4,5,9$ & Medium & YES \\
\hline 4 & Minimization of travel time of travelers & $1,2,4,5,9,10$ & Medium & YES \\
\hline 5 & Efficiency in the public transport of the city & $1,2,4,5,6,9,10$ & Medium & YES \\
\hline 6 & Improvement in the quantity and quality of the city's roads & $1,2,4,5,10$ & Medium & YES \\
\hline 7 & Traffic information at critical points in the city & $1,4,5,9,10$ & High & YES \\
\hline 8 & Increase efficiency in emergency response times & $4,5,6,9,10$ & Medium & YES \\
\hline 9 & Information on the weather in relevant points of the city & $4,6,9,10$ & Low & NO \\
\hline 10 & $\begin{array}{l}\text { Statistical information on the number of passengers transported, } \\
\text { means of transport used, travel times, etc. }\end{array}$ & $1,2,4,5,6,9,10$ & Medium & YES \\
\hline 11 & Information on the state of the roads in the city & $1,2,4,5,6,10$ & Medium & YES \\
\hline 12 & Information about spaces and parking costs available in the city & $1,2,8,10$ & Medium & YES \\
\hline 13 & Improve efficiency in the parking service, mainly in the payment & $1,2,8,10$ & Low & NO \\
\hline 14 & Disminución de la cantidad de emisiones de gases de los vehículos & $1,2,9,10$ & Low & NO \\
\hline
\end{tabular}

Regarding the service areas presented in the ARC-IT (selected reference architecture), we consider it pertinent to exclude services related to the areas of "Commercial vehicle operations", "Vehicle safety", and "Weather". None of services in these areas was considered for ITS architecture of the city, because these are services that do not have a considerable priority for stakeholders, besides, the context of the city makes them little relevant. The services "compliance with the law" and "performance management" identified as a complement to the reference architectures were considered for the ITS architecture of the city.

Finally, 35 services were taken into account for ITS architecture of the city (33 taken from ARCIT and two additional ones from other reference architectures). The list of service is presented in Figure 9.

The other elements that were identified for ITS architecture of the city of Popayán: functional processes, subsystems, physical objects and logical objects, correspond to elements specifically used in the selected reference architecture (ARCIT). The functional processes determined were: provide user services, provide public safety, public transport management, infrastructure management, provide support services, traffic management, archived data management, and performance management. Aforementioned functional processes were selected, because these allow provision of the 35 selected services.

Regarding subsystems required for ITS architecture, we established that the five subsystems proposed by ARC-IT reference architecture are required: support sub-system, sub-system of centers, sub-system of field equipment, sub-system traveler devices and sub-system vehicles. The inclusion of the five subsystems is due to the fact that all are required for the provision of the selected services.

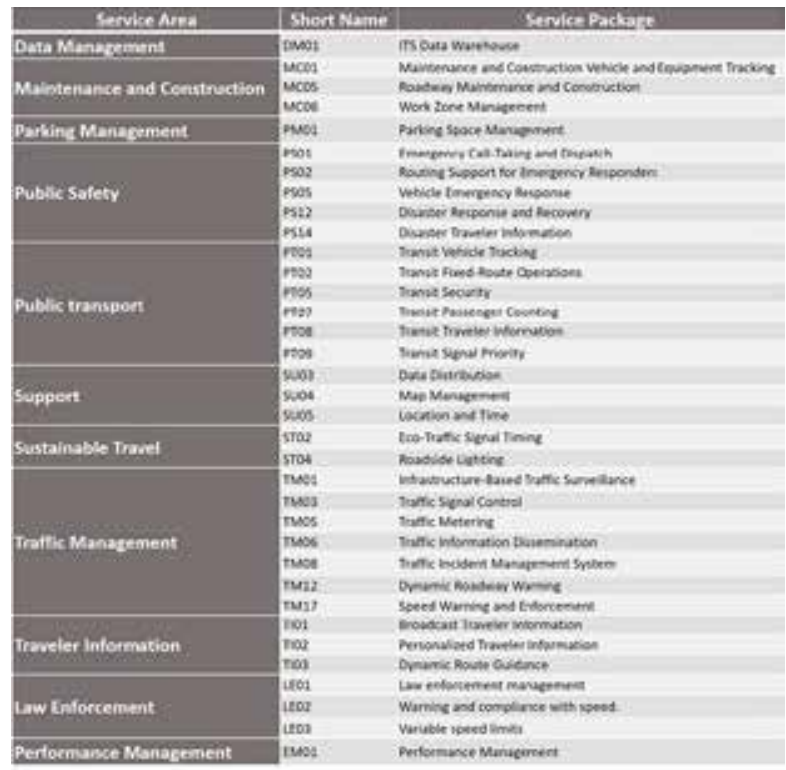

Figure 9. Group of services of ITS architecture 
Only some of physical objects and logical objects presented by the ARC-IT (included as components of the subsystems) were required to design the ITS proposal for the city.

\subsection{Main views of general ITS architecture of the city and detailed architectures by service}

With the identified components, we proceeded to design the views of ITS architecture of Popayán. To present the general views of the architecture, we used diagram types presented in selected reference ITS architecture, in other words, we adapt diagrams of ARC-IT for ITS architecture for Popayán, because these have an adequate level of understanding and a high level of use in the international context.
Initially, we proceeded with the general functional view of ITS architecture, for which the relevant stakeholders and identified functional processes were taken into account. General functional view is presented in Figure 10. The functional view allows to visualize the processes selected, relationships between processes, and between processes and stakeholders.

Actors of system, subsystems and physical objects were taken into account for the general physical viewg. The physical view that we proposed for ITS architecture of Popayán is presented in Figure 11. The general physical view allows to visualize proposed subsystems and physical objects within each subsystem. Physical objects must provide the

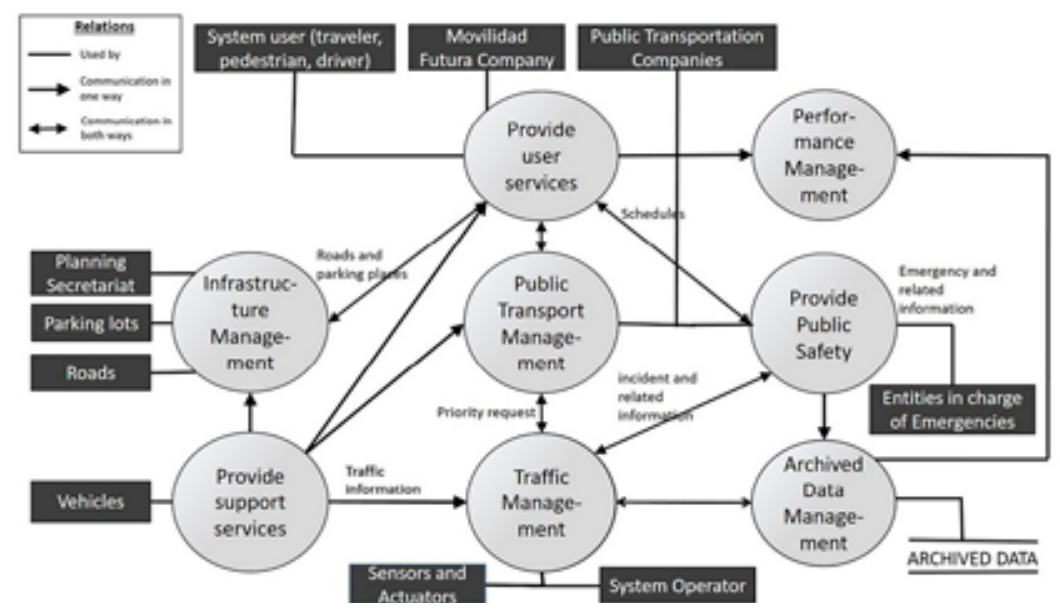

Figure 10. Functional view, general ITS architecture for Popayán.

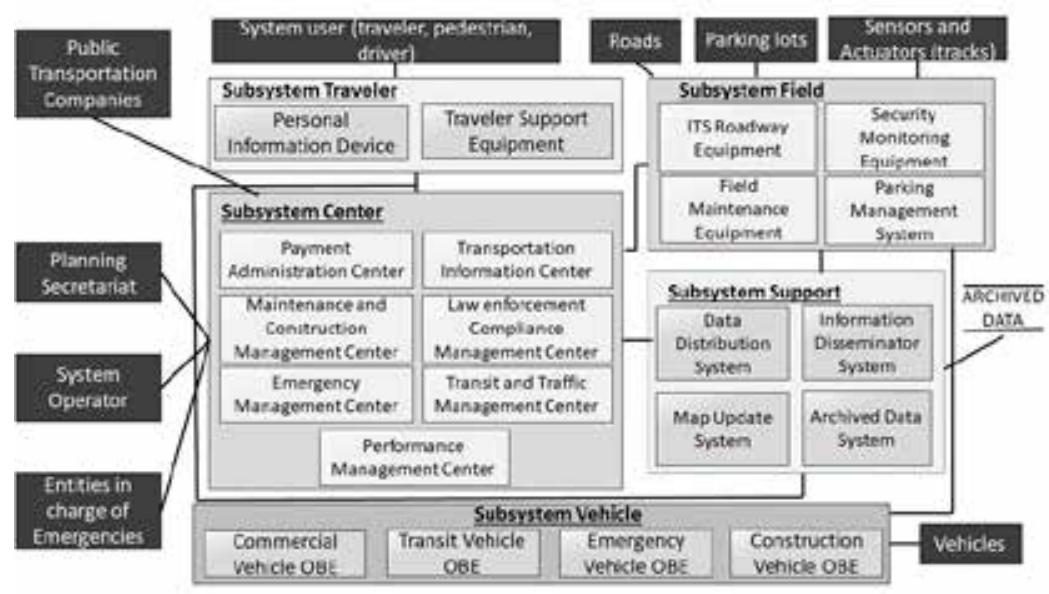

Figure 11. Physical view, general ITS architecture for Popayán 


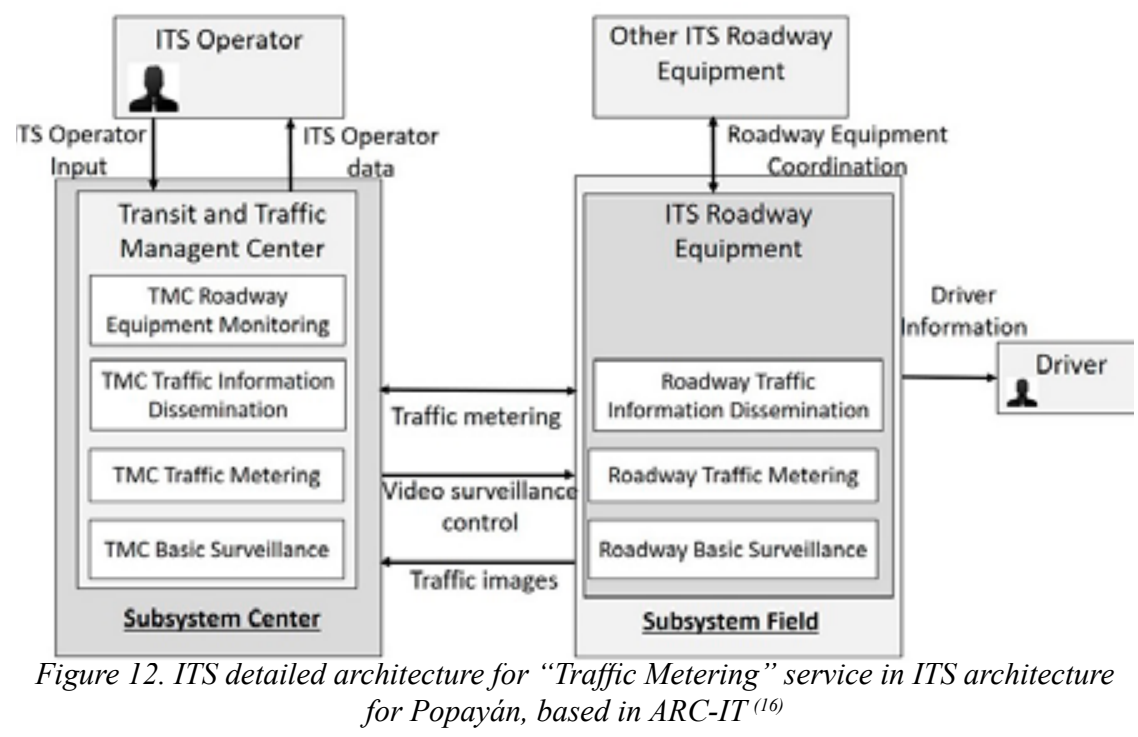

selected services in architecture. In addition to the two views of the general ITS architecture of the city, a detailed service-specific ITS architecture was designed for each of the most relevant services of the 35 selected for the ITS architecture of the city.

The detailed architectures of the services were based on ARC-IT service architecture diagrams, adjusting them according to the general ITS architecture designed for Popayán. An example of the detailed ITS architecture for one of the services is presented in Figure 12.

In detailed ITS architecture of the "Traffic Metering" service (Figure 12), two (Center and Filed) of five subsystems presented in Figure 11 are used. The "center" subsystem uses the physical object "Transit and traffic management center" and the subsystem "field" uses the physical object "ITS Roadway equipment".

Each of the two physical objects uses several logical objects to perform its functionality. The service has two actors, ITS operator and driver.

\section{Discussion}

We considered the methodology developed and details on design of ITS architecture of the city are useful tools for those interested in developing an ITS architecture for a city that has a similar context within the country or in a development country similar to Colombia. In addition, ITS architecture proposed for Popayán can be a reference for development of mobility services for the city, because this architecture defines the needs, priorities and services that need to be implemented, guaranteeing that developments carried out will use standardized elements and exchange of information between these is already defined. We believe that with the information delivered on the proposed methodology and the application case in this document, it is sufficient to apply it in another intermediate city and obtain a similar result, in case it is considered necessary, the interested parties can contact the authors to try to solve any concerns about it.

Our methodology for the design of an ITS architecture and its application for the city of Popayán, have some advantages with respect to what currently exists. First, ITS architecture designed for Popayán city can be used directly for an intermediate city with similar characteristics; while international reference architecture and standards have too large scope and a totally different context of development.

As second advantage, if the intermediate city for which it is wanted to design an ITS architecture, has characteristics that differ considerably from the city that of Popayán, it is possible use the 
proposed methodology to develop another version of ITS architecture that will be more adjusted to the context.

Finally advantage is about ITS architecture references. The use of the methodology proposes the revision of several reference ITS architectures, not just one, which allows to use the best features of each one.

As a final observation, we considered the use of an ITS architecture in a city, developed in an appropriate way (with the help of a methodology and an application example), will allow the prioritization of mobility services to be developed in the city in the short term. It will also facilitate interoperability and integration with existing services and with the services to be developed in the medium and long term. With the implementation of the services developed, it will be possible to find the solution to the most critical problems of an intermediate city, such as death rates due to traffic accidents and high levels of traffic

\section{Conclusions and perspective}

A city that makes an incremental deployment of its portfolio of mobility services requires an ITS architecture that allows the integration and interoperability of new services with the existing technology and services platform.

Having an ITS architecture that recognizes the particular conditions of the city, allows the administration to propose and develop services in a medium and long-term perspective, gradually implementing said mobility services in priority order and in an organized manner.

Using a suitable methodology for the formulation of an ITS architecture, regional or local, is a key aspect that guarantees that the result obtained considers good practices recommended by institutions and / or countries with proven experience and results in the area of intelligent mobility.

As possible future work it is recommended to carry out a technical process for the selection of the reference ITS architecture in the first step of the methodology, in which a statistical analysis can be used to determine what is the difference (gap) between an architecture and another, measure correlations, and obtain a more precise result in this regard.

From the ITS architecture proposed for the city of Popayán, it is necessary to carry out a design and development of services, which seek an improvement in the identified aspects that require urgent attention, such as road safety and proper traffic management.

\section{References}

1. World Health Organization. Global status report on road safety 2015. 2015. [cited 18 jan 2018]. Available in: http://www.who.int/ violence_injury_prevention/road_safety_ status/2015/GSRRS2015_Summary_EN_ final2.pdf?ua $=1$

2. Vargas Castillo AD. Comportamiento de muertesylesiones por accidentes de transporte National Institute of Legal Medicine and Forensic Sciences; c2015. [cited 12 nov 2017]. Available in: http://www.medicinalegal.gov. co/documents/20143/49523/Accidentes $+\mathrm{de}+\mathrm{t}$ ransporte+primera + parte.pdf

3. Valbuena S. Muertes y lesiones no fatales por accidentes de transporte. National Institute of Legal Medicine and Forensic Sciences; c2011. [cited 12 nov 2017]. Available in: http:/www.medicinalegal. gov.co/documents/20143/49511/ Accidentes + De + Transito.pdf

4. Seguí J, Martínez M. Los sistemas inteligentes de transporte y sus efectos en la movilidad urbana e interurbana. Revista electrónica de geografía y Ciencias Sociales. 2004. 8: 170

5. Jesty P, Bossom R. Why do you need an ITS architecture? European and national perspectives. In 4th European Congress 
on Intelligent Transportation Systems and Services; c2004. Budapest, Hungary. Available in: http://frame-online.eu/wpcontent/uploads/2014/10/its-wc-2004-jesty. pdf

6. Qureshi KN, Abdullah AH. A survey on intelligent transportation systems. Middle East Journal of Scientific Research. 2013; 15(5): 629-642. Available in: https://www. researchgate.net/profile/Kashif_Qureshi5/ publication/257367335_A_Survey_on Intelligent_Transportation_Systems/ links/54302df70cf29bbc1276ed6c/A-Surveyon-Intelligent-Transportation-Systems.pdf

7. Yokota T, Weiland R. ITS system architectures for developing countries. World Bank Group; c2004. [cited 21 sep 2017]. Available in: http://siteresources.worldbank. org/EXTROADSHIGHWAYS/Resources/ ITSNote5.pdf

8. U.S. Department of Transportation. Regional ITS architecture guidance: Developing, using, and maintaining an ITS architecture for your region. U.S. Department of Transportation; c2006. [cited 7 oct 2017]. Available in: https://ops.fhwa.dot.gov/publications/ regitsarchguide/raguide.pdf

9. Jesty P, Bosson R. Using the European ITS framework architecture. c2006. [cited 7 oct 2017]. Available in: http://frame-online.eu/ wp-content/uploads/2014/10/its-wc-2006.pdf

10. Bělinová $\mathrm{Z}$, Bures $\mathrm{P}$, Jesty $\mathrm{P}$. Intelligent Transport System Architecture Different Approaches and Future Trends. Switzerland: Springer; 2010, Available in: https://doi. org/10.1007/978-3-642-15503-1_11

11. Mayor's Office of Bogotá (General Secretariat). Qué le aporta el Sistema Inteligente de Transporte (SIT) a la movilidad en Bogotá. Mayor's Office of Bogotá (General Secretariat); c2017. [cited 19 oct 2017].
Available in: http:/www.bogota.gov.co/ article/temas-de-ciudad/movilidad/sistemainteligente-de-transporte-SIT

12. Secretariat of Mobility of Medellín. SITVA, Sistema integrado de transporte del Valle del Aburrá. Secretariat of Mobility of Medellín; c2017. [cited 21 oct 2017]. Available in: https://www.medellin.gov.co/movilidad/ transito-transporte/sitva-sistema-integradode-transporte-del-valle-del-aburra

13. Consensus Systems Technologies (ConSysTec). Arquitectura Nacional ITS de Colombia. c2010.[cited 23 oct 2017]. Available in: http://www.consystec.com/ colombia/web/

14. Pachón Á, Liscano T, Montoya D. Service development model in Intelligent Transportation Systems for Colombian cities. Sistemas \& Telemática. 2015; 13(34): 31-48. Available in: https://doi.org/10.18046/syt. v13i34.2091

15. Giraldo L, Marín C, Bolaños R. Design of an architectural model suitable for Metropolitan West Central Area in Colombia. 23rd ITS World Congress, Melbourne, Australia; 2016. [cited 05 oct 2018]. Available in:https:// www.researchgate.net/profile/Ruben Bolanos/publication/326676247_Design_ of_an_architectural_model_suitable_for_ Metropolitan_West_Central_Area_in_ Colombia/links/5b5d9599a6fdccfob2feeb11/ Design-of-an-architectural-model-suitablefor-Metropolitan-West-Central-Area-inColombia.pdf

16. National ITS Architecture. Architecture Reference for Cooperative and Intelligent Transportation (ARC-IT) [Internet]; c2017. [cited 22 mar 2018]. Available in: http://local. iteris.com/arc-it/

17. European Intelligent Transport Systems (ITS). Framework Architecture [Internet]; 
c2017. FRAME Architecture. [cited 17 nov 2017]. Available in: http://frame-online.eu/

18. International Organization for Standardization (ISO). ISO 14813-1:2015(en) standard, Intelligent transport systems - Reference model architecture(s) for the ITS sector Part 1: ITS service domains, service groups and services; c2017; [cited 23 nov 2017]. Available in: https://www.iso.org/obp/ ui/\#iso:std:iso:14813:-1:ed-2:v1:en
19. Bush T. PESTLE analysis: everything you need to know [Internet]; c2016. [cited 15 nov 2017]. Available in: http://pestleanalysis.com/ pestle-analysis-everything-you-need-know/ internal-pdf://0.0.0.225/pestle-analysiseverything-you-need-know.html 